\title{
Discourse Analysis of Jordanian Online Wedding Invitation Cards During COVID-19 Pandemic
}

\author{
Alaeddin Abdullah Banikalef ${ }^{1}$ \\ ${ }^{1}$ School of English Language and Literature, Faculty of Arts and languages, Jadara University, Jordan. \\ Correspondence: Ala'eddin Banikalef, School of English Language and Literature, Faculty of Arts and \\ languages, Jadara University, Jordan. E-mail: alaeddin@jadara.edu.jo
}

Received: June 1, $2020 \quad$ Accepted: July 4, $2020 \quad$ Online Published: July 14, 2020

doi:10.5539/ijel.v10n5p173 URL: https://doi.org/10.5539/ijel.v10n5p173

\begin{abstract}
The current study analyzed the online wedding invitation genres in Jordan during COVID-19 pandemic. It aims to study the generic structures of these invitations and the role of the socio-cultural-religious norms and beliefs in shaping this type of genre. The corpus of 120 online wedding invitation cards was collected from Facebook from March to June 2020. Data were analyzed based on the framework presented by Swales (1990). Six obligatory and one optional move emerged from the analysis of the data. Through data analysis, it has been found that Jordanians' linguistic behaviors were strongly associated with the religion of Islam and tribalism. Findings from this study have implications for language use and sociolinguistics as well as enhancing the understanding of online wedding invitation practices during a state of a public health emergency.
\end{abstract}

Keywords: COVID-19 pandemic, Jordanian wedding practices, genre analysis, online linguistic behaviors

\section{Introduction}

Weddings are considered as one of the most memorable and happiest experiences in individuals' lives. However, in a time of the coronavirus disease (COVID-19) pandemic, lifestyle in general and wedding practices, in particular, have been changed dramatically. In order to control and prevent the transmission of COVID-19, the Jordanian government has declared a state of emergency on March 16, 2020, as part of a series of measures including military deployments on roads and highways, the suspension of prayers at mosques and churches, preventing wedding events and funeral gatherings, and limiting the size of gatherings to no more than 10 (Al-Khalidi, 2020). Consequently, courts, markets, government offices, transport facilities, retailers, and almost everything else had shut down operations. In other words, the current crisis, like many others has had far-reaching effects beyond the transmission of this disease itself and attempts to quarantine it, including, political cultural and social implications. This means that this pandemic and the social-distancing policies that have taken to control the spread of COVID-19, it has enormous impacts upon the Jordanian social activities in general and on their wedding practices in particular. Since the crisis had been started on 17 March 2020, all Jordanians, including couples would be quarantined for approximately three months at home and traditional wedding practices, with large gatherings of people, had been banned throughout Jordan.

In normal situations, a wedding requires certain preparations, and choosing the wedding invitation card is one of these prior arrangements. Wedding invitation cards are culturally constructed and conventionalized genres. According to Al-ali (2006), the invitation can be written down as well as sent orally. Printed types of invitation may contain a specific generic structure that is different from the typical oral invitation (Faramarzi, Elekaei, \& Tabrizi, 2015). Most wedding cards comprise more certain details among others, such as the names of the bride and groom as well as the date and time of the wedding (Yasmin, Naseem, \& Sohail, 2019). The style of wedding invitation cards varies from time to time and from one community to another. On the occasion of a wedding, Jordanians, for example, use a distinctive style for designing their invitation cards. The study of these cards may help to clarify the primary norms that are embedded in the social norm systems of Arabic society in general and in the Jordanian society in particular. Thus, the current study aims to define the component moves regarding the online Jordanian wedding invitation cards that have been shared on Facebook in the time of COVID-19 pandemic. And, this study will provide valuable insights about Jordanian society in terms of online linguistic behaviors in a particular communication event, as well as the socio-cultural-religious background. 


\subsection{Aims and Objectives of the Study}

This study attempts to achieve the following objectives:

1) To figure out the main moves presented by Jordanian, Jordanian online wedding invitation cards which were posted on Facebook during COVID-19 pandemic.

2) To find out the socio-cultural-religious norms of the Jordanian online wedding invitation cards.

\section{Literature Review}

Genre is a systemic-functional term that is used in literary theory and socio-functional analysis (Duranti, 2009). Imtihani (2010) believes that genre has become the main concept in many areas of contemporary social and cultural analysis. This term is still defined differently from one researcher to another. Martin (1984), for example, defined genre as "a staged, goal-oriented, purposeful activity in which people engage as members of our culture" (p. 25). In line with Martin, Kress (1987) describes genre as "the term which describes that aspect of the form of the texts which is due to the effect of their production in particular social occasions" (p. 36). According to Fairclough (2010), genre is a socially ratified way of using language in connection with particular types of social activity (p. 14). Some other researchers define genre as social actions occurring within a specific historical and socio-cultural context (Bawarshi, 2000; Hamilton, 2016; Miller, 1984).

Studying genre as social actions helps people to understand and account for how speakers perform their everyday tasks through their discursive behaviors. Moreover, it uses to examine discourses features in the broad context of the particular communicative process, and it "tries to offer the rationale of the discourse features in line with writers' publicly retrievable intentions and institutional conventions" (Ruiying \& Allison, 2004, p. 265). Furthermore, genre analysis clarifies why and how language is used in a different social context and describes the language in minor components named moves.

In the Jordanian context, the characteristic uses of language and language behavior including different types of speech acts such as promising, requesting, complaining, warning, refusing, answering, and apologizing and have received abundant attention in the literature (Banikalef \& Bataineh, 2017); substantially less has been paid to online "homely" discourses (Miller, 1984) such as death announcements, birth, and wedding invitation (Sawalmeh, 2018).

The literature review shows that most of the research in the Jordanian context has been done on offline wedding invitation genre and very little or no attention has been paid to examine the online wedding invitation genre. Al-ali (2006), for example, conducted a study to examine the patterns and the socio-cultural norms embedded in the wedding invitation genre. 200 wedding invitation cards were collected from 45 undergraduate Arab students. To this end, data analysis showed that religious background and male kinship play an essential role in creating and outlining text component selection as well as naming practices. Moreover, it has been found that religion has s strong impact on most features of a Moslem's life including writing invitation cards.

In line with Al-ali (2006), Sawalmeh (2018) conducted a study to figure out the main linguistic tools used in the wedding invitation cards and to what extent such tools have a social purpose. In order to achieve the aim of his study, a sample of 200 Jordanian wedding invitation cards was collected and analyzed in line with a model proposed by Bhatia (1993). Findings showed that there is a deep interchange between social and linguistic choices. These findings are consistent with the previous studies and confirmed that the linguistic lexical choices of the wedding invitation card are influenced by the religious backgrounds of the bride and bridegroom. In short, previous research can only be considered the first step towards a more profound understanding of online wedding invitations among Jordanian during COVID-19 pandemic.

\subsection{Theoretical Framework}

The current study explores different representations along with expressions concerning online written wedding invitation cards in Jordan. It aims to figure out the linguistic structures and socio-religious communicative functions that are found in the Jordanian online wedding invitation cards. Therefore, this study used Swales' approach. Swales (1990) proposed a genre move analysis comprising three moves, namely, "establishing a territory, establishing a niche, and occupying the niche" (p. 141). He suggested an approach to scrutinize genre using different "moves within a text". Bhatia (2014), likewise, identified moves as units that have a specific communicative function in a particular text. Thus, each unit performs a particular communicative purpose. This means that each genre is contained of obligatory and optional a series of constituent moves. However, these moves may differ across disciplines and cultures, plus they do not fundamentally appear in a similar sequence.

Bargiela-Chiappini and Nickerson (2014) argue that any genre comprises textual sequences (moves) that can be 
used in the description of how a language works within a particular speech community. Therefore, wedding invitation cards that shared on Facebook were used to identify their generic structures and observed the ways the linguistic components which were used during COVID-19 pandemic. According to Bhatia (2014) and Swales (1990), a move commonly consists of at least one proposition. Nevertheless, it may comprise (one or more) sentences, and even a clause or a phrase. The current study aims to define the constituent move about the Jordanian wedding invitation cards that shared on Facebook during COVID-19 pandemic.

\subsection{Jordanian Wedding Practices}

Jordan is a Middle East country. Although, it has quick developments in many areas of life, the Jordanians keeps observing their old values and traditions (Alsoudi, 2017). A Jordanian wedding is several day events, including preparations and parties. This is a religious practice that is started by asking the woman in front of a witness, if she agrees on the union (Ala'Eddin Banikalef, 2019; Esfandiari, 2017). After a mutual agreement, a wedding is arranged. However, it is worth mentioning that wedding practices in each province of Jordan can vary slightly from city to city in regards to the food preparation or traditional dress. For most of Jordanians and Muslims in general, marriage is considered as a religious requirement and it must be declared publicly. The publicity is usually achieved through sending wedding invitation cards to relatives and friends appealing them to participate in the wedding ceremony. These invitations are usually printed in Arabic language. Each card consists of several elements, including; opening, identifying the celebrating families, identifying the bride and groom, and determining the place and the time of the wedding ceremony( Banikalef \& Naser, 2019; Sawalmeh, 2018). On the other hand, the present study differs from previous studies (e.g., Al-Ali \& Alawneh, 2010; Sawalmeh, 2018) because of its data and methodology.

\section{Methodology}

Facebook as a famous social network is the place from which the corpus is extracted and gathered the current study. As far as data collection is crucial in social research, a total of 120 online wedding invitation cards were collected from March 27, 2020, to June 13, 2020. When the data-collection was completed, an analysis of generic components was done based on the framework presented by Swales (1990). In addition to the schematic structures of the online wedding invitation genre, content and communicative goals were also examined. A critical discourse analysis (CDA) is also performed to find out how religion is associated with the online genre in general and with the wedding invitation cards in particular.

\section{Results and Discussion}

This section discusses the genre analysis of the corpus. As mentioned earlier, the current study applies Swales' (1990) genre approach in order to examine the schematic structures of the online genre of wedding invitation. Other items such as the influence of socio-cultural and the choice of the lexical structure were also investigated.

\subsection{Linguistic Structures of Online Wedding Invitations and Social-Cultural Influences}

Jordanian wedding invitation cards were collected and analyzed in line with Swales' (1990) framework. Seven moves emerged from the study; namely, opening, stating the celebrating tribe, identifying the inviter, stating the bride and groom's first names, stay home, stay safe notes, and stating the date of the ceremony, and closing. However, these seven moves do not essentially arrange in the same order in all examples, as well as not all of them are obligatory.

\subsubsection{Opening}

It is the first obligatory move that appeared in $35 \%$ of the data. It is usually written in the center top of the online wedding invitation card. The main communicative goal of this move is to grab the readers' attention. Data showed that there were three ways, were used by Jordanian couples in opening their online wedding invitations;

1) Ayahs (verses) from the Holy Qur'an appeared in almost 45\% the openings, see the following examples:

$$
\text { ”بسم الله الرحمن الرحيم" }
$$

- (In the name of Allah, the most merciful and the most benevolent)

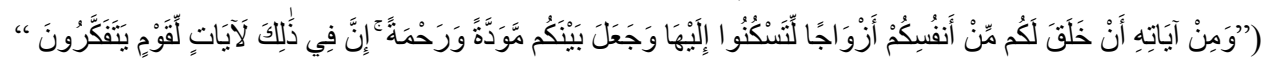

- (And among His Signs is this, that he created for you mates from among yourselves, that ye may dwell in tranquility with them. And he has put love and mercy between your (hearts): verily in that are signs for those who reflect). Surah Al Rum, verse 21

2) Sayings from Prophet Mohammed to bless the bride and the groom as (30\%) of the openings, for example: 


$$
\text { ”خير في اللهم بارك لهما وبارك عليهما واجمع بينهما، }
$$

- (May Allah bless them and shower His blessings upon them, and may He unite them both in goodness).

3) Verses from Arabic poetry occur in $25 \%$ of the openings.

(Do not worry my sweetest

You are in my poetry and in my words

You might grow old in years

But you are ever young in my pages)

\section{Nizar Qabbani}

In short, the frequent use of Quranic verses and the sayings of Prophet Mohammed (PBUH) in the Jordanian online wedding invitations is evidence that Jordanians are obedient to Allah (God) and to Islamic rules that advise people to start everything with the name of God to safeguard it to accomplishment (Yasmin et al., 2019). For Muslims, everything is led according to Islamic values from birth to death. In parallel, as in the real world, data showed that Islamic instructions played a very important role in shaping and creating the Jordanian virtual identity.

\subsubsection{Stating the Celebrating Tribe}

Mentioning the name of celebrating tribe is an optional move that often comes in the second position. It occurs in $15 \%$ of the total data. This move usually appears as a simple noun phrase (e.g., "Afraah" 'Weddings') followed by the groom's tribe name on the top right side of the invitation and the name of the bride's tribe on the top left side of the invitation. The majority of the Jordanian couples used to recognize themselves with their tribe's name (e.g., Afraah asheerat Al Bataineh wa BaniKhalef; weddings of tribe Al Bataineh and tribe BaniKhalef). Consequently, it can be said that the traditional tribe loyalty remains a powerful force in the Jordanian online speech community. That is to say that tribalism has a huge influence over Jordanians' linguistic choices and their views about social life activities including wedding practices.

\subsubsection{Identifying the Inviter}

This is the third obligatory move. The Jordanian online wedding invitation cards are usually printed in the names of the fathers of the groom and bride. Data showed that the name of the groom's father is positioned on the right-hand side whiles the bride's father on the left-hand side. According to Al-Ali (2006, p. 706), "there is a tendency to start with the right-hand words of the print due to the right to left reading orientation in the Arabic language". Therefore, when one is reading the wedding invitation, he/she would more likely to start from the right with the name of the groom's father, which might be more likely to grab the reader's attention.

\subsubsection{Stating the Bride and Groom's First Names}

The fourth move refers to introducing the first name of the bride and groom which is obligatory and was found in all 120 samples. Their names and their titles are usually placed centrally on a parallel line. The data showed that the bride and groom's names were frequently preceded with professional and/or academic titles, which showed their academic degrees, positions, and ranks. The data also revealed that in some samples the name of the bride did not mention. Data showed that 50 out of 120 wedding invitations the name of the bride was not and the word kariimatuh (his daughter) was used instead. The reason refers to the traditional and religious orientations.

\subsubsection{Stay Home, Stay Safe Note}

The fifth obligatory move which is found in all 120 samples of Jordanian online wedding invitation cards, to stay home, stay safe note. This part is important, clearly explains the communicative purpose of a wedding invitation, and requests the invitees to stay safe in their homes away from the coronavirus and pray for (groom and bride) with God's blessings.

\subsubsection{Stating the Date of the Ceremony}

The sixth obligatory move that appeared in Jordanian online wedding invitation cards is stating the date of the ceremony. In addition to the date of the ceremony, this move includes a short note reminding the invitees that the wedding will be done without holding a party because of the coronavirus pandemic.

\subsubsection{Closing}


This is the seventh obligatory moves appeared in all data set. The communicative function of the move is either to wish happiness to the invitees and/or appeal for the invitees to make Dua'a (supplications) for God's blessings to come upon the groom and the bride.

\section{Conclusion}

The coronavirus pandemic has affected just about every area of Jordanians' social lives generally and weeding practices particularly. The current research investigated major component moves of typical Jordanian online wedding invitations during the coronavirus pandemic. It also examined the socio-cultural-religious influence on this genre. The data were analyzed in line with Swales' (1990) genre analysis approach. A sample of 120 online wedding invitation cards was collected from Facebook. Seven component moves emerged from data analysis. The seven obligatory moves were opening, identifying the inviter, stating the bride and groom's first names, stay home, stay safe notes, and stating the date of the ceremony, and closing. On the other hand, stating the name of the celebrating tribe was only the optional move. The general findings indicate that the cultural norms and religious background profoundly rooted in Jordanians can strongly affect their linguistic behaviors during their social practices. Besides religion, tribalism plays a main part in modern Jordanian society and it still has an important authority over Jordanians social activities, including wedding practices. The current study implies its significance in academics. A comparison of different wedding practices between Muslims and Christians living in Jordan is recommended for further research.

\section{References}

Al-ali, M. N. (2006). Religious affiliations and masculine power in Jordanian wedding invitation genre. Discourse \& Society, 17(16), 691-714. https://doi.org/10.1177/0957926506068428

Al-Ali, M. N., \& Alawneh, R. (2010). Linguistic mitigating devices in American and Jordanian students' requests. Intercultural Pragmatics, 7(2), 311-339. https://doi.org/10.1515/iprg.2010.014

Al-Khalidi, S. (2020, March 17). Jordan's monarch announces state of emergency to combat coronavirus. The Thomson Reuters Trust Principles. Retrieved from https://www.reuters.com/article/us-health-coronavirus-jordan/jordans-monarch-announces-state-of-emergen cy-to-combat-coronavirus-idUSKBN2141FA

Alsoudi, K. A. (2017). Features of the Jordanian Cultural Identity in the Islamic Education Books for the Two Phases of Primary and Secondary Education in Jordan. World Journal of Education, 7(2). https://doi.org/10.5430/wje.v7n2p50

Banikalef, A. A. A. (2019). The Impact of Culture and Gender on the Production of Online Speech Acts among Jordanian Facebook Users. International Journal of Arabic-English Studies (IJAES), 19(2), 395-410. https://doi.org/10.33806/ijaes2000.19.2.9

Banikalef, A., \& Bataineh, K. B. (2017). A Sociolinguistic Study of Speech Act Realization Patterns in Jordanians' Facebook Status Updates. International Journal of Linguistics, 9(3), 264-283. https://doi.org/10.5296/ijl.v9i3.11245

Banikalef, A., \& Naser, J. A. (2019). The Difficulties in Translating Culture-Specific Expressions from Arabic into English. Journal of Education and Practice, 10(9), 78-82. https://doi.org/10.7176/JEP

Bargiela-Chiappini, F., \& Nickerson, C. R. (2014). Writing business: Genres, media and discourses. London: Routledge. https://doi.org/10.4324/9781315840246

Bawarshi, A. (2000). The genre function. College English, 62(3), 335-360. https://doi.org/10.2307/378935

Bhatia, V. K. (2014). Analysing genre: Language use in professional settings. London: Routledge. https://doi.org/10.4324/9781315844992

Duranti, A. (2009). Linguistic anthropology: A reader (Vol. 1). New Jersey: John Wiley \& Sons.

Esfandiari, S. (2017, June 9). Wedding, How to Survive a Jordanian. The Culture Trip. Retrieved from https:/theculturetrip.com/middle-east/jordan/articles/how-to-survive-a-jordanian-wedding/

Fairclough, N. (1995). Critical Discourse Analysis: The Critical Study of Language. London: Longman.

Faramarzi, S., Elekaei, A., \& Tabrizi, H. (2015). Genre-based Discourse Analysis of Wedding Invitation Cards in Iran. Journal of Language Teaching and Research, 6(3), 662-668. https://doi.org/10.17507/jltr.0603.25

Hamilton, S. (2016). "[T]o bind together in mutual helpfulness": Genre and/as Social Action in the Victorian Antivivisection Press. The Journal of Modern Periodical Studies, 6(2), 134-160. 
https://doi.org/10.5325/jmodeperistud.6.2.0134

Imtihani, N. (2010). Genre Analysis in the Frame of Systemic. Humaniora, 22(1), 86-93.

Kress, G. (1987). Genre in a social theory of language: A reply to John Dixon. The Place of Genre in Learning: Current Debates, 6(5), 35-45.

Martin, J. R. (1984). Language, register and genre. Children Writing: Reader, 1, 984.

Miller, C. R. (1984). Genre as Social Action. Quarterly Journal of Speech, 70(February), 151-167. https://doi.org/10.1080/00335638409383686

Ruiying, Y., \& Allison, D. (2004). Research articles in applied linguistics: Structures from a functional $\begin{array}{lllll}\text { perspective. English for } & \text { 264-279. }\end{array}$ https://doi.org/10.1016/S0889-4906(03)00005-X

Swales, J. (1990). Genre analysis: English in academic and research settings. Cambridge: Cambridge University Press.

Sawalmeh, M. H. (2018). Jordanian Wedding Invitation as a Genre: An Analysis of Rhetorical Structure and Linguistic Features. International Journal of Linguistics, Literature and Translation (IJLLT), 1(1), 118-126. https://doi.org/10.2139/ssrn.3354508

Yasmin, M., Naseem, F., \& Sohail, A. (2019). Religious and Socio-cultural Influences on the Pakistani Wedding Invitation. De Gruyter, 5(12), 354-368. https://doi.org/10.1515/opli-2019-0019

\section{Copyrights}

Copyright for this article is retained by the author, with first publication rights granted to the journal.

This is an open-access article distributed under the terms and conditions of the Creative Commons Attribution license (http://creativecommons.org/licenses/by/4.0/). 